\title{
EXISTENCE OF A MILD SOLUTION FOR IMPULSIVE NEUTRAL FRACTIONAL DIFFERENTIAL EQUATIONS WITH NONLOCAL CONDITIONS
}

\author{
Alka Chadha And DWiJEndra N. Pandey
}

\begin{abstract}
In the present work, we investigate the existence of a mild solution of the fractional order differential equation with impulsive conditions in a Banach space. We establish the existence of a mild solution by using some fixed point theorems and resolvent operator theory. We present an example for showing the effectiveness of the main theory.
\end{abstract}

Mathematics subject classification (2010): 34K37, 34K40, 34K45, 35R11, 45J05, 45K05.

Keywords and phrases: fractional calculus, multiple base points, resolvent operator, nonlocal conditions, impulsive neutral fractional differential equation.

\section{REFERENCES}

[1] H.M. Ahmed, Fractional neutral evolution equations with nonlocal conditions, Adv. Difference Equ., 2013 (2013), 117.

[2] P. Balasubramaniam, V. Vembarasan, T. Senthilkumar, Approximate controllability of impulsive fractional integro-differential systems with nonlocal conditions in Hilbert space, Numer. Funct. Anal. Optimi., 35 (2014), 177-197.

[3] E. BAZHLekova, Fractional evolution equations in Banach spaces, Ph.D. Thesis, Eindhoven University of Technology, 2001.

[4] M. Benchohra, J. Henderson, S.K. NTOUyas, Impulsive differential equations and inclusions, Contemporary Mathematics and Its Applications, Vol.2, Hindawi Publishing Corporation, New York, 2006.

[5] L. BYSZEWSKI, Theorems about the existence and uniqueness of solutions of a semilinear evolution nonlocal Cauchy problem, J. Math. Anal. Appl., 162 (1991), 497-505.

[6] L. BYSZEWSKI, V. LAKSHMIKANTHAM, Theorem about the existence and uniqueness of a solution of a nonlocal abstract Cauchy problem in a Banach space, Applied Anal., 40 (1990), 11-19.

[7] A. Chadha, D.N. PANDEY, Existence results for an impulsive neutral fractional integrodifferential equation with infinite delay, Int. J. Diff. Equ., 2014 (2014), pp-10.

[8] A. CHADHA, D.N. PANDEY, Existence of a mild solution for an impulsive neutral fractional integrodifferential equation with nonlocal conditions, J. Fract. Cal. Appl., 6 (2015), 5-20.

[9] K. Ezzinbia, X. Fu, K. Hilal, Existence and regularity in the $\alpha$-norm for some neutral partial differential equations with nonlocal conditions, Nonlinear Analysis: TMA, 67 (2007), 1613-1622.

[10] K. EzZINBIA, X. FU, Existence and regularity of solutions for some neutral partial differential equations with nonlocal conditions, Nonlinear Analysis: TMA, 57 (2004), 1029-1041.

[11] S. FARAHI, T. GuendouZI, Approximate controllability of fractional neutral stochastic evolution equations with nonlocal conditions, Results. Math., 2014 (2014), pp-21.

[12] M. FEČKAN, Y. ZHOU, J.-R. WANG, On the concept and existence of solution for impulsive fractional differential equations, Commun Nonlinear Sci Numer Simulat, 17 (2012), 3050-3060.

[13] M. FEČKAN, Y. ZHOU, J.-R. WANG, Response to "Comments on the concept of existence of solution for impulsive fractional differential equations”, Commun Nonlinear Sci Numer Simulat, 19 (2014), 4213-4215. 
[14] T.E. Govindan, An existence result for the Cauchy problem for stochastic systems with heredity, Diff. Int. Equ., 15 (2002), 103-113.

[15] A. Granas, J. Dugundu, Fixed Point Theory, Springer-Verlag, New York, 2003.

[16] K. Karthikeyan, A. Anguraj, K. Malar, J.J. Trujillo, Existence of mild and classical solutions for nonlocal impulsive integrodifferential equations in Banach spaces with measure of noncompactness, Int. J. Diff. Equ., 2014 (2014), pp-10.

[17] A.A. Kilbas, H.M. SRivastava, J.J. Trujillo, Theory and Applications of Fractional Differential Equations, Elsevier, Amsterdam, 2006.

[18] V.B. Kolmanovs Kit, V.R. Nosov, Stability of neutral-type functional differential equations, Nonlinear Analysis: TMA, 6 (1982), 873-910.

[19] V. Lakshmikantham, D. Bainov, P.S. Simeonov, Theory of Impulsive Differential Equations, World Scientific, Singapore-London, 1989.

[20] F. Li, G.M. N'GuereKatA, An existence result for neutral delay integrodifferential equations with fractional order and nonlocal conditions, Abstr. Appl. Anal., Volume 2011 (2011), Article ID 952782, 20 pages.

[21] F. LI, J. LIANG, H.-K. XU, Existence of mild solutions for fractional integrodifferential equations of Sobolev type with nonlocal conditions, J. Math. Anal. Appl., 391 (2012), 510-525.

[22] F. LI, Nonlocal Cauchy problem for delay fractional integrodifferential equations of neutral type, Adv. Diff. Equ., 2012 (2012), pp-23.

[23] Y. LiU, B. Ahmad, A study of impulsive multiterm fractional differential equations with single and multiple base points and applications, The Scientific World Journal, 2014 (2014), pp-28.

[24] K.S. Miller, B. Ross, An Introduction to the Fractional Calculus and Fractional Differential Equations, John Wiley and Sons, Inc. New York, 1993.

[25] M.G. Mophou, Existence and uniqueness of mild solutions to impulsive fractional differential equations, Nonlinear Analysis: TMA, 72 (2010), 1604-1615.

[26] A. PAZY, Semi-groups of Linear operator and Applications of Partial Differential Equations, Springer verlag, 1983.

[27] I. Podlubny, Fractional Differential Equations, Academic press, New York (1993).

[28] J. PRuss, Evolutionary Integral Equations and Applications, in Monographs Math., Vol. 87, Birkhauser-Verlag, 1993.

[29] S.G. Samko, A.A. Kilbas, O.I. Marichev, Fractional Integrals and Derivatives: Theory and Applications, Gordon and Breach Science Publisher, Yverdon, 1993.

[30] X.-B. SHU, Q. WANG, The existence and uniqueness of mild solutions for fractional differential equations with nonlocal conditions of order $1<\alpha<2$, Comp. Math. Appl., 64 (2012), 2100-2110.

[31] X.-B. SHU, Y. LAI, Y. CHEN, The existence of mild solutions for impulsive fractional partial differential equations, Nonlinear Analysis: TMA, 74 (2011), 2003-2011.

[32] G. TR. Stamov, I.M. Stamova, Almost periodic solutions for impulsive fractional differential equations, Dynamical Systems: An International Journal, 29 (2014), 119-132.

[33] V. Vijayakumar, C. Ravichandran, R. Murugesu, J.J. Trujillo, Controllability results for a class of fractional semilinear integro-differential inclusions via resolvent operators, Applied Math. Comp., 247 (2014), 152-161.

[34] G. WAng, B. Ahmad, L. Zhang, J.J. Nieto, Comments on the concept of existence of solution for impulsive fractional differential equations, Commun Nonlinear Sci Numer Simulat, 19 (2014) 401403.

[35] G. WANG, S. Liu, D. Baleanu, L. Zhang, A new impulsive multi-orders fractional differential equation involving multipoint fractional integral boundary conditions, Abstr. Appl. Anal., Volume 2014 (2014), Article ID 932747, 10 pages.

[36] Z. YAN, H. ZHANG, Existence of solutions to impulsive fractional partial neutral stochastic integrodifferential inclusions with state-dependent delay, Elect. J. Diff. Equ., 2013 (2013), 1-21.

[37] Z. YAN, X. JIA, Impulsive problems for fractional partial neutral functional integro-differential inclusions with infinite delay and analytic resolvent operators, Mediterr. J. Math., 2013 (2013), 1-36.

[38] X. Zhang, X. HuAng, Z. LiU, The Existence and uniqueness of mild solutions for impulsive fractional equations with nonlocal conditions and infinite delay, Noninear Analysis: Hybrid Systems, 4 (2010), 775-781.

[39] L. ZHU, G. LI, Existence results of semilinear differential equations with nonlocal initial conditions in Banach spaces, Nonlinear Analysis: TMA, 74 (2011), 5133-5140. 
Differential Equations \& Applications www.ele-math.com dea@ele-math.com 